\title{
The Effects of Long-term Medication Use in Alzheimer Disease
}

Steven Karceski, MD

Neurology ${ }^{\circledR}$ 2021;96:e2247-e2250. doi:10.1212/WNL.0000000000011843

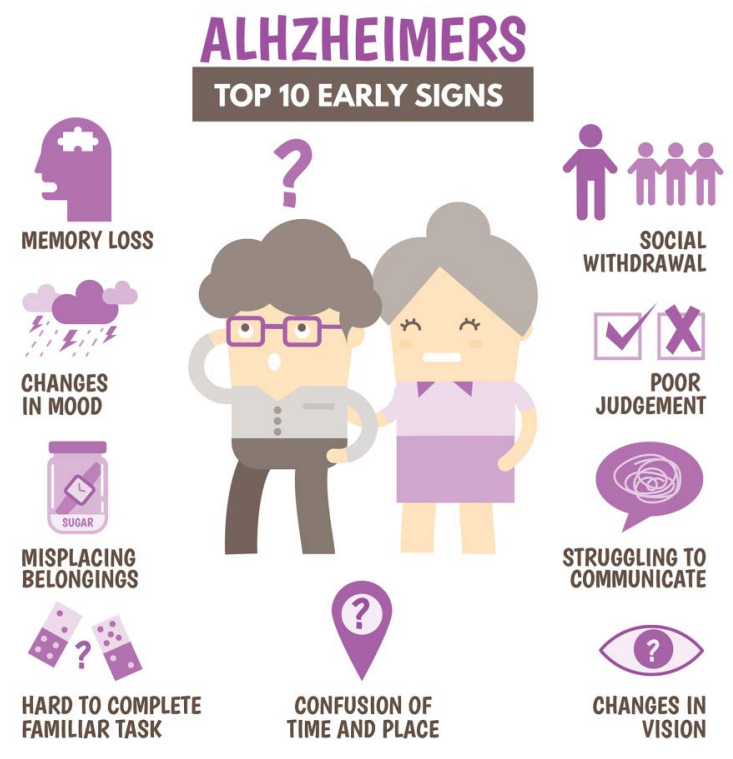

Related Article

Long-term Effects

of Cholinesterase

Inhibitors on

Cognitive Decline and Mortality

http://dx.doi.org/10.1212/

WNL.0000000000011832

Of the many causes of dementia, Alzheimer disease (AD) is the most common. Diagnosis is generally followed by treatment. One of the most common treatments of AD is a type of medication called acetylcholinesterase inhibitors (ChEls). ChEls work by blocking the breakdown of a chemical in the brain called acetylcholine. In doing so, the medication allows more of this chemical to be available in the brain. This can improve or maintain cognition and memory.

Several ChEls are approved for AD treatment. Some examples are donepezil, galantamine, and rivastigmine. Most studies about these drugs have looked at their effectiveness when they are taken for up to 1 year. However, few studies have looked at how these drugs affect AD when they are taken for longer than 1 year. This was the reason that Xu et al. ${ }^{1}$ started their study, as described in their article that appears in this issue of Neurology ${ }^{\circledR}$. They looked at how ChEls affect AD when taken for an average of 5 years. The investigators looked at 3 end points: Did the ChEls reduce the rate of cognitive decline? Did they reduce the risk of developing severe dementia? Did they reduce the risk of death?

\section{How Was the Study Done?}

The authors used information from a database that was started in Sweden in 2007. The database is called the Swedish Dementia Registry (SveDem). Between 2007 and 2017, 78,346 people who were diagnosed with dementia were entered into the SveDem database. There were several causes of dementia that were represented in the group. The 2 most common were Alzheimer dementia (31\%) and mixed Alzheimer dementia (19\%). These types were followed by unspecified dementia (23\%), vascular dementia (19\%), Lewy body dementia (2\%), frontotemporal dementia (2\%), Parkinson disease with dementia (2\%), and other (2\%). For their study, Xu and colleagues ${ }^{1}$ included all patients from the database who had either Alzheimer dementia or mixed Alzheimer dementia, for a total of 39,196 people. The researchers also excluded people for whom data critical to the study were not listed. These data included age, sex, and a clear diagnosis. 
The researchers identified 11,652 people from the database who were taking a ChEl. They then compared them to 5,826 people who had been diagnosed with mild to moderate AD, but who were not taking a ChEl. Sixty-two percent of the group were women. On average, their age was between 75 and 87 years. Among ChEl users, $62 \%$ were taking donepezil, $21 \%$ were taking galantamine, and $17 \%$ were taking rivastigmine. The researchers found that the most common conditions group members had in addition to $A D$ or dementia were high blood pressure (74\%), stroke (17\%), diabetes $(16 \%)$, irregular heart rate $(16 \%)$, and cancer (16\%).

\section{What Did the Study Show?}

In their study, the researchers found that some people in the group taking medication for their $A D$ developed severe $A D$ less often than the nonusers. The researchers looked at the effects of each medication separately. They found that those who were taking galantamine had a lower risk of developing severe dementia. This difference did not occur for the other 2 medications they studied (rivastigmine and donepezil).

\section{Medication and the Risk of Death}

During an average of 5 years of follow-up, 6,055 (35\%) of the patients who were studied died. This overall mortality rate was about 2 times higher than that of the general Swedish population. When comparing the groups within the study, the researchers found that there was a $27 \%$ lower risk of death for ChEl users compared with nonusers. In addition, they found that the dose of the medication being taken had an effect on this risk as well. People who took higher doses of the ChEls had a lower mortality risk. The risk for people taking galantamine was lower at any dosage level. In addition, the study showed that people taking more than $7.5 \mathrm{mg}$ of donepezil or more than $9.5 \mathrm{mg}$ of rivastigmine had a lower mortality risk than those taking a lower dose of those medications.

\section{Strengths and Limitations of the Study}

One of the most important differences between the study by Xu et al. ${ }^{1}$ and prior research that has been done on this topic is the duration of the study. First, the SveDem database allowed $\mathrm{Xu}$ and colleagues ${ }^{1}$ to follow patients for an average of 5 years during treatment. This is much longer than previous studies, most of which ended at 1 year. Second, the number of patients was much larger than prior studies. One of the limitations of this study is that, although it showed a lower mortality rate in the group taking $A D$ medication, the database did not allow for the researchers to identify cause of death. In other words, it was not possible to know for sure that AD was the cause of death for those who died during the course of the study. However, the study did show that the people taking ChEls experienced long-term benefits. This group also had a lower overall mortality risk. Finally, the researchers found that some people had a lower risk of developing severe dementia when taking galantamine. 


\section{About Alzheimer Disease and Dementia}

\section{What Is Dementia? What Is Alzheimer Disease?}

Alzheimer disease (AD) is the most common cause of dementia. Dementia is defined as "a condition that affects memory and thinking." When it is more severe, dementia interferes with a person's daily life. However, it takes a long time for a person with dementia to become impaired. Modern research suggests that dementia takes years to develop. Some estimates suggest that the loss of brain function happens over the course of 1-2 decades. A person with dementia starts out with typical thinking abilities, and very gradually develops problems with memory. Misplacing keys, forgetting appointments, and mixing up details (like in a recipe) are common. It is easy to see how a person with mild dementia could overlook these concerns and attribute them to just getting older.

When a person has dementia, the trouble with thinking and memory is very subtle at first. At this stage, is called mild cognitive impairment. Later, as the dementia worsens, a person has a harder time performing complex tasks. Cooking, and the planning that is required to complete such a task, becomes harder. Tasks like keeping track of bills, appointments, and friends' names get more difficult as well. When the condition is more severe, a person's judgment is affected. Emotions can change, most often coming out as depression. A person's language can become impaired, and they can have increasing trouble finding the right word to say. At some point, the thought processes are so severely affected that the person can no longer complete usual daily activities.

It is at the point when the problem significantly affects the person's daily life that the term dementia is used. There are many different causes of dementia. Of these, $A D$ is the most common. Because of this, people often use the terms dementia and AD interchangeably. About 5.5 million Americans have AD. It is estimated that more than 360,000 new cases occur each year. This number will probably increase as the population ages, because aging itself is a major risk factor for the development of $A D$. AD is the sixth leading cause of death for adults. It kills more than 100,000 Americans each year. $^{2}$

\section{What Are the Symptoms?}

Loss of recent memories (also called short-term memory) is one of the earliest signs of dementia. For instance, the person may repeat stories in the same conversation. They may forget the details of the previous day, such as where they went. They may not recall the details of a movie they recently watched. Other signs include frequently misplacing belongings or having difficulty doing familiar tasks, even things they may have done many times before. They might have trouble finding the right words to say and may not follow the details of long conversations. For some people, there can also be changes in mood, behavior, or personality.

Because dementia and $A D$ are so gradual, in the early stages, many people fail to recognize that something is wrong. They may assume that such behavior is a normal part of getting older, or that they are "just having a senior moment." Although forgetting things is common, if it is something that is getting worse, it may be a sign of a more serious problem. The key to treatment of $A D$ is early diagnosis. It is critical to see a doctor when one recognizes or suspects AD symptoms.

\section{How Is AD Diagnosed?}

When AD is suspected, it is important to have a complete medical and neurologic workup. In the first doctor's visit, a detailed history and examination are needed. Often, blood tests are ordered, and brain imaging studies are requested (such as an MRI). Additional testing, such as a PET scan, can help in making the diagnosis. Neuropsychological testing is often performed. This is done both to help make the diagnosis and to follow how the person's brain function changes over time. In some people, a lumbar puncture (also known as a spinal tap) may be needed. This may be done to rule out illnesses that can mimic AD.

\section{What Causes AD?}

The cause of $A D$ is not fully known. It is not contagious. Although genetic forms of $A D$ have been identified, the most common form does not run in families.

\section{What Are the Treatments?}

Although there is currently no cure for $A D$, there are treatments that may help with the symptoms of AD.

\section{Memory Symptoms}

The cognitive symptoms of AD should be treated as early as possible to slow the progression of the disease. Drugs called cholinesterase inhibitors (such as those described in the study by Xu et al. ${ }^{1}$ ) may be considered in people with mild to moderate disease. Vitamin E may also slow 
progression but should only be used if prescribed by a doctor.

\section{Behavioral Problems}

Behaviors such as suspicion, paranoia, aggression, or resistance to care may be treated first by understanding what triggers these behaviors. Caregivers may learn how to change things in the person's environment to avoid or minimize these triggers. Some examples include providing low lighting and music to improve eating, taking regular walks, scheduling toileting, and following consistent routines. Sometimes, medications are needed to help with mood problems such as depression.

\section{Prevention}

Ongoing research suggests that there are many ways to keep your brain healthy. Avoiding harmful substances such as alcohol and drugs and exercising the body regularly have been shown to preserve brain function. It is also important to exercise the mind. Social interactions, reading, and playing games are just a few ways that we can constantly challenge our brains, keeping them healthy for as long as possible.

\section{For More Information:}

Brain \& Life

brainandlife.org

\section{Alzheimer's Association}

alz.org/

\section{Alzheimer's Foundation of America alzfdn.org/}

\section{References}

1. $\mathrm{Xu} \mathrm{H}$, Garcia-Ptacek S, Jönsson L, Wimo A, Nordström $P$, Eriksdotter $M$. Long-term effects of cholinesterase inhibitors on cognitive decline and mortality. Neurology 2021; 96:e2220-e2230.

2. Centers for Disease Control and Prevention. Alzheimer's disease. Available at: cdc.gov/dotw/alzheimers/. Accessed February 21, 2021. 


\section{Neurology}

\section{The Effects of Long-term Medication Use in Alzheimer Disease Steven Karceski \\ Neurology 2021;96;e2247-e2250 \\ DOI 10.1212/WNL.0000000000011843}

This information is current as of April 26, 2021

\section{Updated Information \&} Services

References

Permissions \& Licensing

Reprints including high resolution figures, can be found at: http://n.neurology.org/content/96/17/e2247.full

This article cites 1 articles, 1 of which you can access for free at: http://n.neurology.org/content/96/17/e2247.full\#ref-list-1

Information about reproducing this article in parts (figures,tables) or in its entirety can be found online at:

http://www.neurology.org/about/about_the_journal\#permissions

Information about ordering reprints can be found online:

http://n.neurology.org/subscribers/advertise

Neurology ${ }^{\circledR}$ is the official journal of the American Academy of Neurology. Published continuously since 1951 , it is now a weekly with 48 issues per year. Copyright @ 2021 American Academy of Neurology. All rights reserved. Print ISSN: 0028-3878. Online ISSN: 1526-632X.

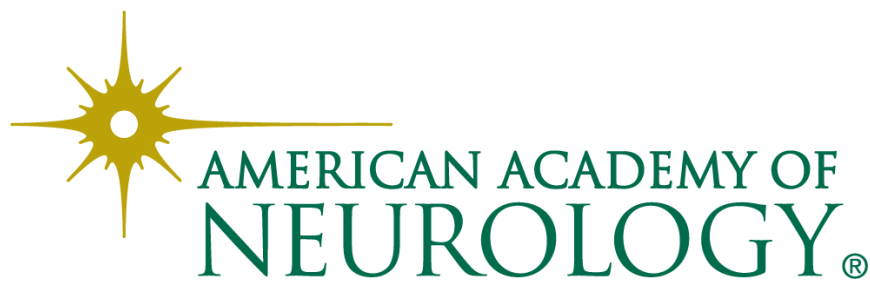

